\title{
Resting Left Ventricular Dyssynchrony and Mechanical Reserve in Asymptomatic Normotensive Subjects with Early Type 2 Diabetes Mellitus
}

\author{
Ragab A. Mahfouz Elshaimaa A. Seaoud Radwa A. Elbelbesy \\ Islam E. Shehata \\ Department of Cardiology, Faculty of Medicine, Zagazig University, Zagazig, Egypt
}

\begin{abstract}
Keywords
Dyssynchrony - Contractile reserve $\cdot$ Mechanical reserve $\cdot$ Diabetes mellitus - Coronary flow Subclinical cardiomyopathy
\end{abstract}

\begin{abstract}
Background: Most diabetic patients have silent ischemia and cardiac dysfunction that is usually observed in the late phase of the disease when it becomes clinically obvious. We hypothesized that left ventricular dyssynchrony (LVdys) (or dispersion) is an early marker of myocardial involvement in asymptomatic early type 2 diabetes mellitus (T2DM) patients. Therefore, we aimed to detect early markers of myocardial dysfunction in early T2DM using LVdys and left ventricular mechanical reserve (LVMR). Methods: We examined 91 consecutive subjects with early T2DM with speckle tracking imaging to evaluate LVdys and with dobutamine stress to evaluate LVMR (defined as left ventricular mechanical reserve global longitudinal strain $\left[\mathrm{LVMR}_{\mathrm{GLS}}\right] \geq 2 \%$ ). Our patients were divided into two groups according to LVdys: group 1 with LVdys ( $n=49)$, and group 2 without LVdys $(n=42)$. Results: We found that 49 (54\%) subjects in our cohort had resting LVdys (standard deviation of tissue synchronization of the 12 left ventricular segments [Ts-SD-12] $\geq 34.2 \mathrm{~ms}$ ). GLS and strain rate were comparable at rest between patients with and without LVdys. On the other hand, LVMR was blunted in those with LVdys $(p<0.001)$. We found that HbA1c, high-sensitivity C-reactive protein, and left atrial volume index were inversely correlated with LVMR. Multivariate analysis showed that LVdys was the strongest predictor $(p<0.001)$ of blunted LVMR. Using receiver operating characteristic curve analysis, we found that a Ts-SD-12 $\geq 36.5 \mathrm{~ms}$ was the best cutoff value to predict blunted LVMR (area under the curve $=0.89, p<0.001$ ). Conclusion: The LVdys (Ts-SD-12) cutoff $\geq 36.5 \mathrm{~ms}$ was the optimal value for prediction of impaired LVMR and might be an early marker of subclinical cardiac dysfunction and risk stratification of subjects with asymptomatic early T2DM with preserved left ventricular ejection fraction.

(C) 2020 S. Karger AG, Basel
\end{abstract}

Dr. Islam E. Shehata, MD

Department of Cardiology, Faculty of Medicine

Zagazig University

Zagazig 44519 (Egypt)

iemshehata@ @u.edu.eg or dr-islam-shehata @ hotmail.com 


\begin{tabular}{l|l}
\hline Pulse 2020;8:47-56 \\
\hline DOI: 10.1159/000506712 & $\begin{array}{l}\text { @ 2020 S. Karger AG, Basel } \\
\text { www.karger.com/pls }\end{array}$ \\
\hline
\end{tabular}

Mahfouz et al.: Resting Left Ventricular Dyssynchrony and Mechanical Reserve in Asymptomatic Normotensive Subjects with Early Type 2 Diabetes Mellitus

\section{Introduction}

Diabetic individuals often have silent ischemia and cardiac dysfunction that is usually observed in the late phase of the disease when it becomes clinically obvious [1]. There is a common consensus that firm control of cardiac risk factors in type 2 diabetes mellitus (T2DM) lessens the occurrence of cardiovascular disease [2].

Patients with dilated or secondary cardiomyopathy usually have dynamic asynchrony [3] and decreased contractile and mechanical reserve of the left ventricle [4,5]. Previous studies focused mainly on the influence of left ventricular dyssynchrony (LVdys) in persons who have heart failure. LVdys has been shown to predict clinical events and to guide and assess patient outcome after cardiac resynchronization therapy $[6,7]$.

We hypothesized that LVdys (or dispersion) is an early marker of myocardial involvement in asymptomatic patients with DM. Therefore, we aimed to detect early markers of myocardial dysfunction in early T2DM using LVdys and left ventricular mechanical reserve (LVMR).

\section{Materials and Methods}

The present comparative cross-sectional study was conducted from August 2018 to September 2019 at the Department of Cardiology of the Faculty of Medicine, Zagazig University, Zagazig, Egypt.

\section{Inclusion Criteria}

We examined 91 consecutive non-obese, normotensive asymptomatic patients with a $<5$ years' history of T2DM (early T2DM) with speckle tracking imaging to evaluate LVdys and with dobutamine stress to evaluate LVMR (defined as left ventricular mechanical reserve global longitudinal strain $\left[\mathrm{LVMR}_{\mathrm{GLS}}\right] \geq 2 \%$ ). Our patients were divided into two groups according to LVdys: group 1 with LVdys $(n=49)$ and group 2 without LVdys $(n=42)$. The patients' age was $43 \pm 12$ years and $63 \%$ were male.

\section{Exclusion Criteria}

We excluded patients who had coronary artery disease (i.e., who had positive stress thallium study), hypertension (i.e., blood pressure $>140 / 90 \mathrm{~mm} \mathrm{Hg}$ ), valvular diseases, or significant rhythm disturbances including paroxysmal atrial fibrillation. In addition, obese subjects (i.e., body mass index $\geq 30$ ) and patients with type $1 \mathrm{DM}$, impaired kidney function (i.e., serum creatinine $>1.5 \mathrm{mg} / \mathrm{dL}$ ), congenital heart disease, and poor technical image quality that may result in pseudodyssynchrony were also excluded.

\section{Echocardiography}

All participants underwent conventional Doppler echocardiographic evaluation using a Vivid 7 ultrasound system (GE Healthcare, Waukesha, WI, USA). Standard echocardiographic views were obtained and stored digitally. All echocardiographic parameters and left ventricular assessments were carried out according to the American Society of Echocardiography guidelines [8]. The mitral valve diastolic wave velocities E and A were obtained. Moreover, the mitral annulus wave velocities e' and a' were measure. Then, the E/e' ratio was calculated as a surrogate marker of left ventricular end-diastolic pressure [9].

\section{Speckle Tracking Echocardiography}

Speckle tracking evaluation of LVdys was performed by recording with the use of customized software with the Echo PAC workstation (GE Healthcare) and a high frame rate (80-100 frames/s) in the three apical views at the end of expiration. Our acquisition frame rates were adequate to allow satisfactory tracking capture peak exercise strain and strain rate (SR) reliably at the higher heart rates when dobutamine was administered. Typically the frame rate was adjusted to be about $70 \%$ of the heart rate. Three consecutive cardiac cycles were recorded for average evaluation and quantification of systolic strain parameters. The left ventricular boundary was outlined in the three apical views. Then the area of interest was determined and adjusted to endocardial border until optimal tracking. We calculated the average strain and SR at the end of systole. An automatically generated region of interest was divided into six segments. The left ventricular peak longitudinal systolic strain and the left ventricular peak longitudinal systolic SR were calculated. The averages of the all values derived from the three apical views were the final strain parameters [10].

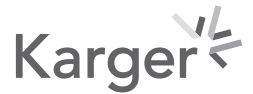




\begin{tabular}{l|l}
\hline Pulse 2020;8:47-56 \\
\hline DOI: 10.1159/000506712 & $\begin{array}{l}\text { (c) 2020 S. Karger AG, Basel } \\
\text { www.karger.com/pls }\end{array}$ \\
\hline
\end{tabular}

Mahfouz et al.: Resting Left Ventricular Dyssynchrony and Mechanical Reserve in Asymptomatic Normotensive Subjects with Early Type 2 Diabetes Mellitus

Table 1. Baseline characteristics of patients with and without LVdys

\begin{tabular}{|c|c|c|c|}
\hline & $\begin{array}{l}\text { Patients with } \\
\text { LVdys ( } n=49 \text { ) }\end{array}$ & $\begin{array}{l}\text { Patients without } \\
\text { LVdys }(n=42)\end{array}$ & $p$ value \\
\hline Age, years & $44 \pm 13$ & $45 \pm 11$ & 0.15 \\
\hline Sex, male/female (males) & $28 / 21(57 \%)$ & 25/17 (59\%) & 0.46 \\
\hline Body mass index & $26.1 \pm 4.3$ & $26.5 \pm 3.9$ & 0.41 \\
\hline Smokers & $43 \%$ & $31 \%$ & 0.12 \\
\hline Family history of CAD & $27 \%$ & $22 \%$ & 0.28 \\
\hline Heart rate, bpm & $79 \pm 11$ & $75 \pm 11$ & 0.07 \\
\hline Systolic blood pressure, mm Hg & $116 \pm 11$ & $107 \pm 9$ & 0.09 \\
\hline Diastolic blood pressure, $\mathrm{mm} \mathrm{Hg}$ & $70 \pm 8$ & $71 \pm 8$ & 0.65 \\
\hline QRS duration, ms & $95.7 \pm 4.5$ & $96.3 \pm 5.35$ & 0.10 \\
\hline Glucose, mg/dL & $139 \pm 27$ & $125 \pm 22$ & $<0.08$ \\
\hline $\mathrm{HbA1c} \%$ & $7.8 \pm 2.2$ & $7.1 \pm 2.3$ & $<0.03$ \\
\hline hsCRP, mg/dL & $3.9 \pm 1.7$ & $1.3 \pm 0.4$ & $<0.01$ \\
\hline LDL-C, mg/dL & $98 \pm 27$ & $101 \pm 31$ & 0.12 \\
\hline $\mathrm{HDL}-\mathrm{C}, \mathrm{mg} / \mathrm{dL}$ & $41 \pm 11$ & $46 \pm 9$ & 0.15 \\
\hline Total cholesterol, mg/dL & $189 \pm 33$ & $185 \pm 35$ & 0.09 \\
\hline Triglyceride, mg/dL & $143 \pm 59$ & $137 \pm 67$ & 0.15 \\
\hline Serum creatinine, $\mathrm{mg} / \mathrm{dL}$ & $1.20 \pm 0.09$ & $1.08 \pm 0.09$ & 0.33 \\
\hline
\end{tabular}

CAD, coronary artery disease; HDL-C, high-density lipoprotein cholesterol; hsCRP, high-sensitivity C-reactive protein; LDL-C, low-density lipoprotein cholesterol; LVdys, left ventricular dyssynchrony.

\section{Assessment of Left Ventricular Asynchrony}

We followed the model using six basal and six mid segments for estimation of the four parameters of systolic dyssynchrony, which included the standard deviation of tissue synchronization of the 12 left ventricular segments (Ts-SD-12), the maximum tissue synchronization between any two left ventricular segments, the standard deviation of tissue synchronization of the 6 basal left ventricular segments, and the maximum difference in tissue synchronization between any 2 of the 6 basal left ventricular segments [11]. Ts-SD-12 is the frequently accepted value for LVdys [12].

In our study the opposing wall delays in all patients also tracked similar to standard deviation of peak strain in 12 segments. The pattern of dyssynchrony was most of the delayed or dyssynchronous segments in the nonseptal distribution.

\section{Dobutamine Stress Echocardiography}

Dobutamine stress echocardiography was performed to evaluate LVMR for all participants in the stepwise high-dose dobutamine protocol. Any subjects taking a beta-blocker were instructed to stop it for $72 \mathrm{~h}$ prior to dobutamine stress echo. Initially we started with a dose of $5 \mathrm{mg} / \mathrm{kg} / \mathrm{min}$, which increased incrementally every $10 \mathrm{~min}$ until a maximum dose of $40 \mu \mathrm{g} / \mathrm{kg} / \mathrm{min}$ [13]. The conventional echo measurements and speckle tracking parameters were evaluated at rest and at the maximum dose of $40 \mu \mathrm{g} / \mathrm{kg} / \mathrm{min}$ dobutamine. After that, the values obtained at rest were subtracted from the values of the maximum $40 \mu \mathrm{g} / \mathrm{kg} /$ min dobutamine dose. At peak stress two-dimensional imaging of the left ventricle was obtained from the three apical views in order to evaluate left ventricular strain and left ventricular ejection fraction (LVEF). The absolute increase in GLS, LVEF, and SR were calculated as the LVMR parameters (defined as an LVMR $\mathrm{GLS}$ $\geq 2 \%$ ).

\section{Coronary Angiography}

All participants underwent control coronary angiography. Standard angiographic views were obtained and digitally stored. None of the subjects had significant coronary artery disease.

\section{Statistics}

Variables were expressed as mean \pm standard deviation. Percentage was used for categorical variables and $t$ test for comparison. Univariate analysis was performed for testing the predictors of blunted mechanical 


\begin{tabular}{l|l}
\hline Pulse 2020;8:47-56 \\
\hline DOI: 10.1159/000506712 & $\begin{array}{l}\text { @ 2020 S. Karger AG, Basel } \\
\text { www.karger.com/pls }\end{array}$ \\
\hline
\end{tabular}

Mahfouz et al.: Resting Left Ventricular Dyssynchrony and Mechanical Reserve in Asymptomatic Normotensive Subjects with Early Type 2 Diabetes Mellitus

Table 2. Resting echocardiographic and LVdys parameters in diabetic patients

\begin{tabular}{|c|c|c|c|}
\hline & $\begin{array}{l}\text { Patients with } \\
\text { LVdys ( } n=49 \text { ) }\end{array}$ & $\begin{array}{l}\text { Patients without } \\
\text { LVdys }(n=42)\end{array}$ & $p$ value \\
\hline LVEF, \% & $67.5 \pm 6.3$ & $66.9 \pm 6.7$ & 0.40 \\
\hline LVMI (M-mode), g/m² & $72.1 \pm 12.5$ & $70.9 \pm 12.7$ & 0.32 \\
\hline $\mathrm{LAVI}, \mathrm{mL} / \mathrm{m}^{2}$ & $28.9 \pm 6.8$ & $27.3 \pm 5.9$ & 0.14 \\
\hline $\mathrm{E}, \mathrm{cm} / \mathrm{s}$ & $71 \pm 15$ & $72 \pm 15$ & 0.37 \\
\hline $\mathrm{A}, \mathrm{cm} / \mathrm{s}$ & $63 \pm 8$ & $62 \pm 7$ & 0.19 \\
\hline $\mathrm{E} / \mathrm{A}$ ratio & $1.09 \pm 0.3$ & $1.1 \pm 0.3$ & 0.25 \\
\hline$S^{\prime}$ velocity, cm/s & $8.2 \pm 1.8$ & $8.9 \pm 1.5$ & 0.23 \\
\hline $\mathrm{e}^{\prime}$ velocity, $\mathrm{cm} / \mathrm{s}$ & $10.3 \pm 2.0$ & $10.5 \pm 1.9$ & 0.25 \\
\hline $\mathrm{E} / \mathrm{e}^{\prime}$ & $6.1 \pm 1.3$ & $5.6 \pm 1.1$ & 0.31 \\
\hline Ts-SD-12 & $49.5 \pm 8.2$ & $21.2 \pm 5.5$ & $<0.003$ \\
\hline Ts -12 & $143.5 \pm 32.7$ & $105.3 \pm 29.5$ & $<0.001$ \\
\hline Ts-SD-6 & $46.9 \pm 13.5$ & $26.4 \pm 5.3$ & $<0.005$ \\
\hline Ts-6 & $132.6 \pm 23.7$ & $98.2 \pm 20.5$ & $<0.001$ \\
\hline
\end{tabular}

LAVI, left atrial volume index; LVdys, left ventricular dyssynchrony; LVEF, left ventricular ejection fraction; LVMI, left ventricular mass index; Ts-12, maximum Ts between any two left ventricular segments; Ts-6, maximum difference in tissue synchronization between any 2 of the 6 basal left ventricular segments; Ts-SD-12, standard deviation of tissue synchronization of the 12 left ventricular segments; Ts-SD-6, standard deviation of tissue synchronization of the 6 basal left ventricular segments.

reserve among asymptomatic diabetic subjects. Then, the significant univariate predictors were assessed by multivariate linear regression analysis to find out the independent predictors of blunted mechanical reserve. Receiver operating characteristic curve was used to characterize the best cutoff value of Ts-SD-12 to predict blunted LVMR. Data analyses were performed with SPSS version 21.0 (SPSS Inc., Chicago, IL, USA).

\section{Results}

Our study showed that 49 (54\%) patient had LVdys $\geq 34.2 \mathrm{~ms}$. The baseline characteristics and resting LVdys parameters are represented in Table 1 . Table 2 summarizes the resting echocardiographic and LVdys parameters of the study cohort. Figure 1 represents an example of a patient without LVdys, while Figure 2 shows an example of a patient with LVdys.

We found that LVEF was not very different in both groups. However, cardiac output was different in both groups as it was related with difference in heart rate (Table 3).

During rest there was no significant difference in GLS or SR between both groups. However, during dobutamine stress GLS $(p<0.01)$ and SR $(p<0.05)$ considerably increased, and consequently LVMR was significantly increased in subjects without LVdys (absolute increase in GLS $p<0.001$ and absolute increase in SR $p<0.01$ ). Contrarily, LVMR was blunted in patients with LVdys (the absolute increase in GLS in subjects without LVdys was $2.91 \pm$ $1.6 \%$ compared to $1.62 \pm 1.3 \%$ in patients with LVdys; $p<0.001$ ).

Table 4 represents the correlation analysis between Ts-SD-12 and other studied variables in asymptomatic subjects with DM. LVMR was negatively linked with Ts-SD-12 ( $r=$ $-0.78, p<0.001)$, HbA1c $(r=-0.41, p<0.01)$, and high-sensitivity C-reactive protein $(r=$ $-0.31, p<0.05$ ).

With univariate analysis, QRS complex duration $(p<0.01)$, HbA1c $(p<0.05)$, high-sensitivity C-reactive protein $(p<0.03)$, left atrial volume index $(p<0.05), \mathrm{E} / \mathrm{e}^{\prime}$ ratio $(p<0.05)$, and resting LVdys ( $p<0.001)$ were predictors of reduced LVMR. On the other hand, multi- 


\begin{tabular}{ll}
\cline { 2 - 2 } Pulse 2020;8:47-56 \\
\cline { 2 - 2 } DOl: 10.1159/000506712 & $\begin{array}{l}\text { @) 2020 S. Karger AG, Basel } \\
\text { www.karger.com/pls }\end{array}$ \\
\hline
\end{tabular}

Mahfouz et al:: Resting Left Ventricular Dyssynchrony and Mechanical Reserve in Asymptomatic Normotensive Subjects with Early Type 2 Diabetes Mellitus

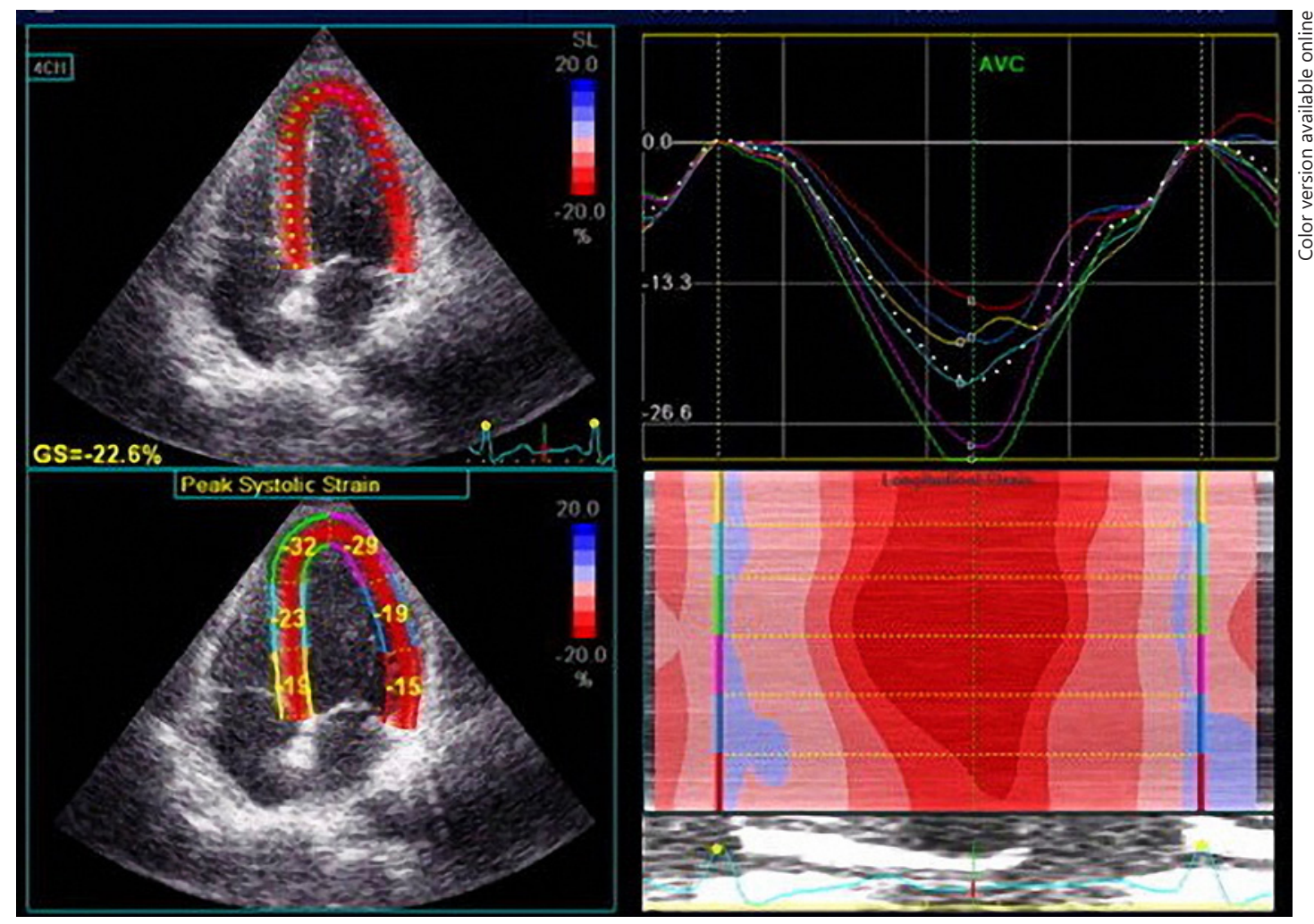

Fig. 1. Two-dimensional STE measurement of longitudinal strain in apical four-chamber view in an asymptomatic diabetic patients without LVdys showing reduction in peak longitudinal strain of basal segments of septal and lateral walls (Esys $=-14 \%$ and $-15 \%$, respectively) but normal peak longitudinal strain of the remaining myocardial segments and normal global left ventricular strain (global strain $[\mathrm{GS}]=-22 \%$ ). AVC, aortic valve closure; LVdys, left ventricular dyssynchrony.

variate linear regression analysis revealed that resting LVdys (OR $=6.45, p<0.001)$ was independently associated with reduced LVMR among asymptomatic subjects with DM (Table 5).

The receiver operating characteristic curve showed that Ts-SD-12 $\geq 36.5 \mathrm{~ms}$ was the best cutoff value to predict reduced mechanical reserve in asymptomatic subjects with DM (area under the curve $=0.89(p<0.001)$, 88\% sensitivity, 95\% specificity) (Fig. 3).

\section{Discussion}

We found that $54 \%$ of diabetic patients had resting LVdys. Moreover, resting LVdys was significantly associated with blunted LVMR. Interestingly, LVdys $\geq 36.5 \mathrm{~ms}$ was the optimal value for prediction of impaired LVMR of early T2DM, which is novel for our study.

Our results showed a relationship between LVdys and LVMR; the possible mechanism for this could be that LVdys results in pathological changes in myocardium, such as microvascular ischemia/silent ischemia, inflammatory changes, and/or fibrosis.

We found that LVEF is not very different in both groups. However, cardiac output was different in both groups as it was related with difference in heart rate (Table 3 ). Left ventricular contractile reserve is generally/traditionally associated with change in global left ventricular function as evidenced by LVEF. Previous papers have used the term LVMR to define changes in SR or strain with stress [14], so we separated contractile reserve from mechanical reserve.

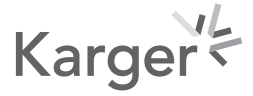




\begin{tabular}{l|l}
\hline Pulse 2020;8:47-56 \\
\hline DOI: 10.1159/000506712 & $\begin{array}{l}\text { @ 2020 S. Karger AG, Basel } \\
\text { www.karger.com/pls }\end{array}$ \\
\hline
\end{tabular}

Mahfouz et al.: Resting Left Ventricular Dyssynchrony and Mechanical Reserve in Asymptomatic Normotensive Subjects with Early Type 2 Diabetes Mellitus

Table 3. Echocardiographic parameters at rest and peak stress according to the presence of LVdys

\begin{tabular}{|c|c|c|c|}
\hline & $\begin{array}{l}\text { Patients with } \\
\text { LVdys ( } n=49)\end{array}$ & $\begin{array}{l}\text { Patients without } \\
\text { LVdys }(n=42)\end{array}$ & $p$ value \\
\hline GLS at rest, $\%$ & $24.1 \pm 2.5$ & $23.9 \pm 2.8$ & 0.61 \\
\hline GLS at $40 \mu \mathrm{g} / \mathrm{kg} / \mathrm{min}$ of DSE, $\%$ & $25.7 \pm 2.7$ & $26.8 \pm 2.5$ & $<0.05$ \\
\hline$\Delta \mathrm{GLS}, \%$ & $1.62 \pm 1.3$ & $2.91 \pm 1.6$ & $<0.001$ \\
\hline SR at rest, $\mathrm{s}^{-1}$ & $-1.35 \pm 0.21$ & $-1.38 \pm 0.20$ & 0.22 \\
\hline SR at $40 \mu \mathrm{g} / \mathrm{kg} / \mathrm{min}$ of DSE, $\mathrm{s}^{-1}$ & $-1.59 \pm 026$ & $-1.77 \pm 0.24$ & 0.01 \\
\hline$\Delta \mathrm{SR}, \mathrm{s}^{-1}$ & $0.28 \pm 0.22$ & $0.39 \pm 0.21$ & 0.01 \\
\hline LVEF at rest, $\%$ & $67.5 \pm 6.4$ & $68.1 \pm 6.5$ & 0.40 \\
\hline LVEF at $40 \mu \mathrm{g} / \mathrm{kg} / \mathrm{min}$ DSE, \% & $71.3 \pm 6.5$ & $72.0 \pm 6.7$ & 0.37 \\
\hline$\triangle \mathrm{LVEF}, \%$ & $3.7 \pm 6.02$ & $3.9 \pm 6.29$ & 0.88 \\
\hline$s^{\prime}$ & $8.13 \pm 1.39$ & $8.15 \pm 1.35$ & 0.09 \\
\hline \multicolumn{4}{|l|}{ Cardiac output, L/min } \\
\hline At rest & $5.1 \pm 1.1$ & $5.2 \pm 1.2$ & 0.13 \\
\hline At exercise & $7.3 \pm 1.9$ & $9.6 \pm 2.4$ & $<0.05$ \\
\hline \multicolumn{4}{|l|}{ Heart rate, bpm } \\
\hline At rest & $79 \pm 11$ & $75 \pm 11$ & 0.07 \\
\hline At exercise & $180 \pm 13$ & $150 \pm 10$ & $<0.05$ \\
\hline
\end{tabular}

DSE, dobutamine stress echocardiography; GLS, global longitudinal strain; LVdys, left ventricular dyssynchrony; LVEF, left ventricular ejection fraction; SR, strain rate.

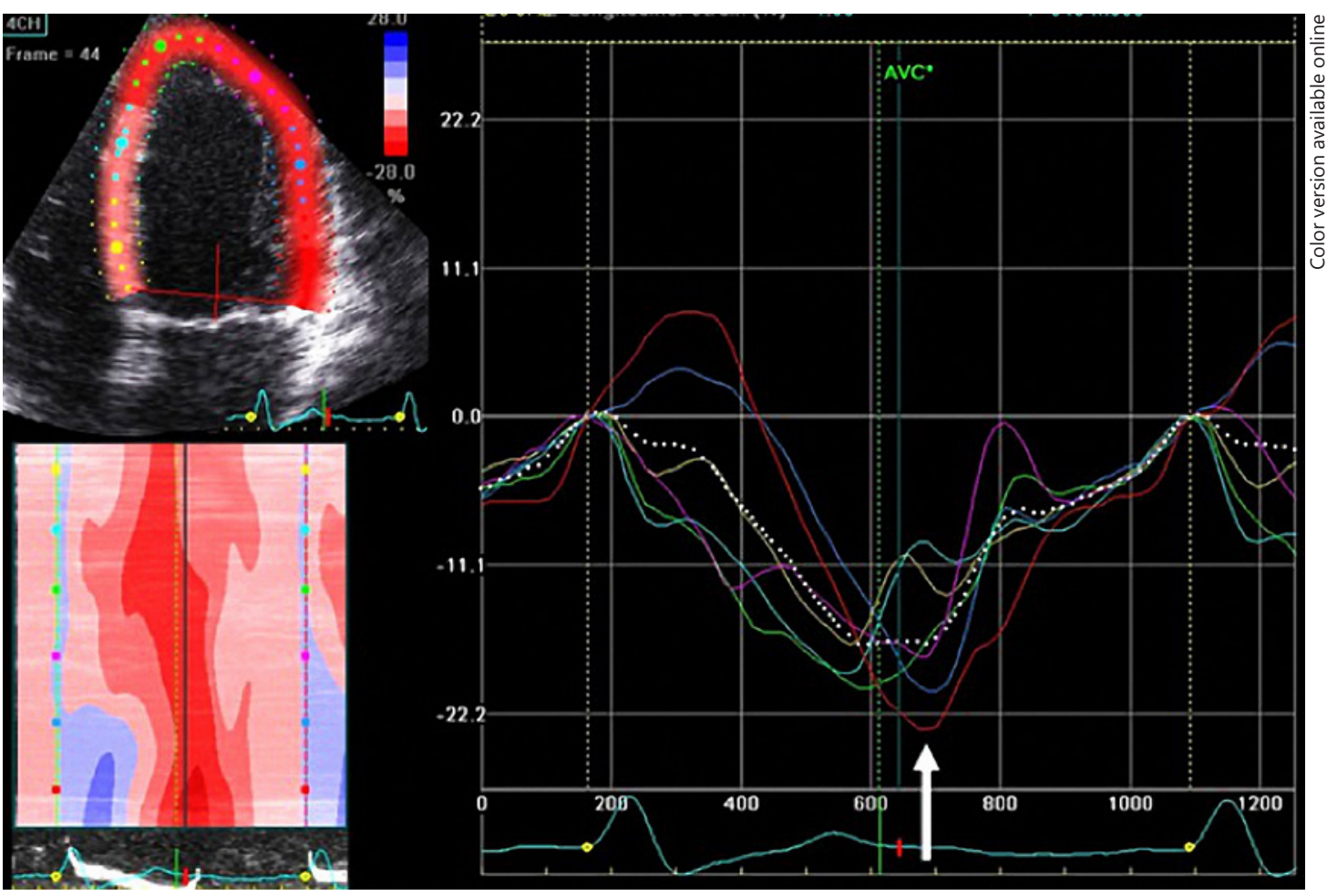

Fig. 2. LVdys demonstrated by speckle tracking echocardiography in asymptomatic diabetic patients. The arrow indicates delayed contraction in the lateral segments (red, blue, and pink strain curves). AVC, aortic valve closure; LVdys, left ventricular dyssynchrony. 


\begin{tabular}{l|l}
\hline Pulse 2020:8:47-56 \\
\hline DOI: 10.1159/000506712 & $\begin{array}{l}\text { (c) 2020 S. Karger AG, Basel } \\
\text { www.karger.com/pls }\end{array}$ \\
\hline
\end{tabular}

Table 4. Correlation between LVMR and other variables

Mahfouz et al.: Resting Left Ventricular Dyssynchrony and Mechanical Reserve in Asymptomatic Normotensive Subjects with Early Type 2 Diabetes Mellitus

\begin{tabular}{lrl}
\hline Variable & $r$ & $p$ value \\
\hline HbA1c, \% & -0.41 & $<0.01$ \\
hsCRP & -0.31 & $<0.05$ \\
E/e' & 0.45 & $<0.01$ \\
Ts-SD-12 & -0.78 & $<0.001$ \\
\hline
\end{tabular}

hsCRP, high-sensitivity C-reactive protein; LVMR, left ventricular mechanical reserve; Ts-SD-12, standard deviation of tissue synchronization of the 12 left ventricular segments.

Table 5. Uni- and multivariate predictors of blunted global longitudinal end-systolic strain reserve ( $\Delta$ GLS) in asymptomatic patients with early T2DM

\begin{tabular}{|c|c|c|c|c|}
\hline & \multicolumn{2}{|l|}{ Univariate } & \multicolumn{2}{|l|}{ Multivariate } \\
\hline & OR (95\% CI) & $p$ value & OR (95\% CI) & $p$ value \\
\hline Age & $0.94(0.85-1.13)$ & 0.75 & $0.94(0.85-1.13)$ & 0.75 \\
\hline Male sex & $0.55(0.29-1.08)$ & 0.08 & $0.55(0.29-1.08)$ & 0.08 \\
\hline QRS duration & $2.56(1.45-4.73)$ & $<0.01$ & $2.56(1.45-4.73)$ & $<0.01$ \\
\hline HbA1c & $2.21(0.95-2.19)$ & $<0.05$ & $2.21(0.95-2.19)$ & $<0.05$ \\
\hline hsCRP & $2.09(1.19-6.11)$ & $<0.05$ & $2.09(1.19-6.11)$ & $<0.05$ \\
\hline LAVI & $2.16(1.13-4.41)$ & $<0.05$ & $2.16(1.13-4.41)$ & $<0.05$ \\
\hline $\mathrm{E} / \mathrm{e}^{\prime}$ & $2.75(1.25-4.60)$ & $<0.05$ & $2.75(1.25-4.60)$ & $<0.05$ \\
\hline Resting LVdys & $8.17(3.35-21.28)$ & $<0.001$ & $6.45(2.31-20.35)$ & $<0.001$ \\
\hline
\end{tabular}

GLS, global longitudinal strain; hsCRP, high-sensitivity C-reactive protein; LAVI, left atrial volume index; LVdys, left ventricular dyssynchrony; T2DM, type 2 diabetes mellitus.

This is particularly important since there was normal contractile reserve but abnormal mechanical reserve in the patients with LVdys.

In subjects with DM, coronary artery disease is frequently missed or identified late due to the frequent silent ischemia and atypical presentation. Hence, diffuse multivessel atherosclerosis often occurs before clinical manifestation or symptoms [15]. Therefore, early diagnosis of myocardial involvement via evaluation of LVdys could provide a clue of subclinical myocardial dysfunction.

Left ventricular asynchrony is clearly recognized as an important contributor to global left ventricular systolic dysfunction $[16,17]$. As a consequence of left ventricular dyssynchronous contraction, left ventricular pressure generation becomes ineffective, resulting in inefficient stroke volume and cardiac output [18].

In DM, there is a pronounced inflammatory status combined with elevated glucose levels resulting in subendocardial interstitial fibrotic changes and consequently longitudinal dyssynchrony [19].

In metabolic disorders, myocardial steatosis leads to fibrotic changes, which results in a dyssynchronous left ventricular contraction that might impair myocardial function [20]. Furthermore, hyperglycemia and inflammation may cause direct injury to cardiomyocytes as well as calcium cycling dysfunction and elevated cytokine levels [21].

Malik etal. [22] demonstrated that long history of DM and microvasculature dysfunction was significantly linked with dyssynchronous left ventricular contraction. They also found 
Mahfouz et al.: Resting Left Ventricular Dyssynchrony and Mechanical Reserve in

Fig. 3. Receiver operating characteristic curve showing the cutoff value of Ts-SD-12 to predict the blunted left ventricular mechanical reserve. AUC, area under the curve; Ts-SD-12, standard deviation of tissue synchronization of the 12 left ventricular segments.

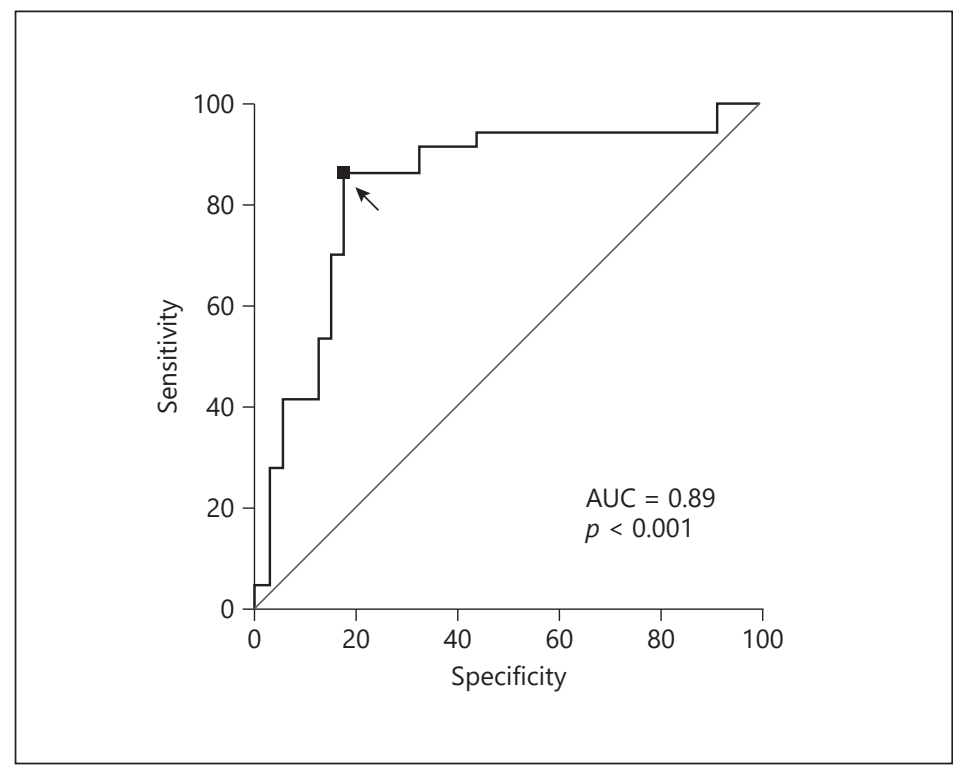

a significant correlation between ventricular dyssynchrony and major cardiovascular events, despite normal perfusion and normal ejection fraction. This association is most likely a reflection of endothelial or microvascular dysfunction in the coronary microvasculature.

We found that patients with LVdys had higher HbA1c values compared with those without LVdys. Furthermore, HbA1c values were significantly correlated with LVdys. These findings highlighted the importance of good control of diabetic status.

Investigators have emphasized that subclinical left ventricular dysfunction was frequently encountered in asymptomatic patients with T2DM [23, 24]. Several mechanisms act synergistically and contribute in the genesis of this subclinical myocardial functional impairment. Hyperglycemia is an important trigger for a variety of pathophysiological responses [25]. These reactions results in apoptotic changes and disruption of the cardiac fibers and consequently an accelerated fibrotic process that contributes to LVdys and myocardial dysfunction.

Holland et al. [26] demonstrated that asymptomatic subjects with T2DM had a high prevalence of subclinical left ventricular dysfunction despite preserved ejection fraction. Furthermore, they stated that left ventricular GLS was found to be an independent predictor of adverse events in addition to systolic blood pressure and HbA1c.

\section{Clinical Implications}

Given its incremental predictive value, improved left ventricular GLS may have a role in reducing the progression to diabetic cardiomyopathy and evident heart failure. We found that early identification of LVdys as an early marker of subclinical cardiac dysfunction might be of value for patients with early T2DM. For that, it might be a significant predictor for discovery of subclinical diabetic cardiomyopathy in early stages of DM and could help in the prevention of heart failure.

HbA1c is related with LVMR, so tight control of blood glucose could change LVdys and LVMR in T2DM. Further larger studies are needed to confirm that aggressive treatment of T2DM and control of HbA1c alter LVdys and outcome. 
Mahfouz et al.: Resting Left Ventricular Dyssynchrony and Mechanical Reserve in Asymptomatic Normotensive Subjects with Early Type 2 Diabetes Mellitus

\section{Conclusion}

The LVdys (Ts-SD-12) cutoff of $\geq 36.5$ ms was the optimal value for prediction of impaired LVMR and might be an early marker of subclinical cardiac dysfunction and risk stratification of subjects with asymptomatic early T2DM with preserved LVEF.

\section{Study Limitations}

The findings of our study should be considered in the light of certain limitations: (1) The sample size was small; a study with a larger sample size is required for further assessment and confirmation of results. (2) The study involved a single cardiac center atZagazig University in Egypt, hence multicentric validation across the country is required for authentication. (3) This study did not involve identification of long-term implications of developing heart failure in T2DM patients with LVdys. A further follow-up of patients would have delineated the same. (4) Further larger studies are needed to confirm that aggressive treatment of T2DM and control of HbA1c alter LVdys and outcome. (5) The incremental value of dyssynchrony or strain change with exercise over resting strain or SR needs to be investigated with more follow-up of clinical outcome data.

\section{Statements of Ethics}

All procedures followed were in accordance with the ethical standards of the responsible committee on human experimentation (institutional and national) and with the Helsinki Declaration of 1964 and later revisions. The protocol was approved by the Zagazig University Institutional Review Board, which confirmed that all methods were performed in accordance with the relevant guidelines and regulations. Informed consent for being included in the study was obtained from all patients.

\section{Disclosure Statement}

I.E. Shehata, E.A. Seaoud, R.A. Elbelbesy, and R.A. Mahfouz declare that they have no conflict of interest.

\section{Funding Sources}

The study received no funding.

\section{Data Availability}

The prospective case-control study data used to support the findings of this study are available from the corresponding author upon request.

\section{References}

1 Wackers FJ, Young LH, Inzucchi SE, Chyun DA, Davey JA, Barrett EJ, et al. Detection of Ischemia in Asymptomatic Diabetics Investigators. Detection of silent myocardial ischemia in asymptomatic diabetic subjects: the DIAD study. Diabetes Care. 2004 Aug;27(8):1954-61.

2 Gaede P, Vedel P, Larsen N, Jensen GV, Parving HH, Pedersen O. Multifactorial intervention and cardiovascular disease in patients with type 2 diabetes. N Engl J Med. 2003 Jan;348(5):383-93.

3 D’Andrea A, Caso P, Cuomo S, Scarafile R, Salerno G, Limongelli G, et al. Effect of dynamic myocardial dyssynchrony on mitral regurgitation during supine bicycle exercise stress echocardiography in patients with idiopathic dilated cardiomyopathy and "narrow" QRS. Eur Heart J. 2007 Apr;28(8):1004-11. 


\begin{tabular}{l|l}
\hline Pulse 2020;8:47-56 \\
\hline DOI: 10.1159/000506712 & $\begin{array}{l}\text { @ 2020 S. Karger AG, Basel } \\
\text { www.karger.com/pls }\end{array}$ \\
\hline
\end{tabular}

Mahfouz et al.: Resting Left Ventricular Dyssynchrony and Mechanical Reserve in

Asymptomatic Normotensive Subjects with Early Type 2 Diabetes Mellitus

4 Roche SL, Vogel M, Pitkänen O, Grant B, Slorach C, Fackoury C, et al. Isovolumic acceleration at rest and during exercise in children normal values for the left ventricle and first noninvasive demonstration of exerciseinduced force-frequency relationships. J Am Coll Cardiol. 2011 Mar;57(9):1100-7.

5 Aljaroudi WA, Hage FG, Hermann D, Doppalapudi H, Venkataraman R, Heo J, et al. Relation of left-ventricular dyssynchrony by phase analysis of gated SPECT images and cardiovascular events in patients with implantable cardiac defibrillators. J Nucl Cardiol. 2010 Jun;17(3):398-404.

6 Malhotra S, Pasupula D, Sharma R, et al. Left ventricular dyssynchrony predicts ventricular tachyarrhythmia inpatients with severely reduced ejection fraction. J Nucl Cardiol. 2013 May;54(Suppl 2):240.

7 Friehling M, Chen J, Saba S, Bazaz R, Schwartzman D, Adelstein EC, et al. A prospective pilot study to evaluate the relationship between acute change in left ventricular synchrony after cardiac resynchronization therapy and patient outcome using a single-injection gated SPECT protocol. Circ Cardiovasc Imaging. 2011 Sep; 4(5): 532-9.

8 Lang RM, Badano LP, Mor-Avi V, Afilalo J, Armstrong A, Ernande L, et al. Recommendations for cardiac chamber quantification by echocardiography in adults: an update from the American Society of Echocardiography and the European Association of Cardiovascular Imaging. Eur Heart J Cardiovasc Imaging. 2015 Mar;16(3):23370.

9 Nagueh SF. Echocardiographic assessment of left ventricular relaxation and cardiac filling pressures. Curr Heart Fail Rep. 2009 Sep;6(3):154-9.

10 Voigt JU, Pedrizzetti G, Lysyansky P, Marwick TH, Houle H, Baumann R, et al. Definitions for a common standard for 2D speckle tracking echocardiography: consensus document of the EACVI/ASE/Industry Task Force to standardize deformation imaging. Eur Heart J Cardiovasc Imaging. 2015 Jan;16(1):1-11.

11 Leong DP, Hoogslag GE, Piers SR, Höke U, Thijssen J, Marsan NA, et al. The relationship between time from myocardial infarction, left ventricular dyssynchrony, and the risk for ventricular arrhythmia: speckle-tracking echocardiographic analysis. J Am Soc Echocardiogr. 2015 Apr;28(4):470-7.

12 Sun JP, Xu TY, Lee AP, Yang XS, Liu M, Li Y, et al. Early diastolic dyssynchrony in relation to left ventricular remodeling and function in hypertension. Int J Cardiol. 2015 Jan;179:195-200.

13 Das SR, Drazner MH, Yancy CW, Stevenson LW, Gersh BJ, Dries DL. Effects of diabetes mellitus and ischemic heart disease on the progression from asymptomatic left ventricular dysfunction to symptomatic heart failure: a retrospective analysis from the Studies of Left Ventricular Dysfunction (SOLVD) Prevention trial. Am Heart J. 2004 Nov;148(5):883-8.

14 Geyer H, Caracciolo G, Abe H, Wilansky S, Carerj S, Gentile F, et al. Assessment of myocardial mechanics using speckle tracking echocardiography: fundamentals and clinical applications. J Am Soc Echocardiogr. 2010 Apr; 23(4):351-69.

15 Vernooy K, Verbeek XA, Peschar M, Crijns HJ, Arts T, Cornelussen RN, et al. Left bundle branch block induces ventricular remodelling and functional septal hypoperfusion. Eur Heart J. 2005 Jan;26(1):91-8.

16 Spragg DD, Leclercq C, Loghmani M, Faris OP, Tunin RS, DiSilvestre D, et al. Regional alterations in protein expression in the dyssynchronous failing heart. Circulation. 2003 Aug;108(8):929-32.

17 Tan HW, Zheng GL, Li L, Wang ZH, Gong HP, Zhang Y, et al. Impaired left ventricular synchronicity in hypertensive patients with ventricular hypertrophy. J Hypertens. 2008 Mar;26(3):553-9.

18 Spragg DD, Kass DA. Pathobiology of left ventricular dyssynchrony and resynchronization. Prog Cardiovasc Dis. 2006 Jul-Aug;49(1):26-41.

19 Martinez DA, Guhl DJ, Stanley WC, Vailas AC. Extracellular matrix maturation in the left ventricle of normal and diabetic swine. Diabetes Res Clin Pract. 2003 Jan;59(1):1-9.

20 Tigen K, Karaahmet T, Kirma C, Dundar C, Pala S, Isiklar I, et al. Diffuse late gadolinium enhancement by cardiovascular magnetic resonance predicts significant intraventricular systolic dyssynchrony in patients with nonischemic dilated cardiomyopathy. J Am Soc Echocardiogr. 2010 Apr;23(4):416-22.

21 Clark RJ, McDonough PM, Swanson E, Trost SU, Suzuki M, Fukuda M, et al. Diabetes and the accompanying hyperglycemia impairs cardiomyocyte calcium cycling through increased nuclear O-GlcNAcylation. J Biol Chem. 2003 Nov;278(45):44230-7.

22 Malik D, Mittal BR, Sood A, Parmar M, Kaur K, Bahl A. Prognostic value of left ventricular mechanical dyssynchrony indices in long-standing type II diabetes mellitus with normal perfusion and left ventricular systolic functions on SPECT-MPI. J Nucl Cardiol. doi: 10.1007/s12350-018-1436-z [Epub ahead of print].

23 Fang ZY, Yuda S, Anderson V, Short L, Case C, Marwick TH. Echocardiographic detection of early diabetic myocardial disease. J Am Coll Cardiol. 2003 Feb;41(4):611-7.

24 Fang ZY, Schull-Meade R, Downey M, Prins J, Marwick TH. Determinants of subclinical diabetic heart disease. Diabetologia. 2005 Feb;48(2):394-402.

25 Aneja A, Tang WH, Bansilal S, Garcia MJ, Farkouh ME. Diabetic cardiomyopathy: insights into pathogenesis, diagnostic challenges, and therapeutic options. Am J Med. 2008 Sep;121(9):748-57.

26 Holland DJ, Marwick TH, Haluska BA, Leano R, Hordern MD, Hare JL, et al. Subclinical LV dysfunction and 10-year outcomes in type 2 diabetes mellitus. Heart. 2015 Jul;101(13):1061-6.

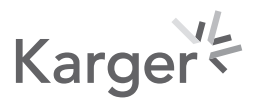

